\title{
Synthesis and Characterization of a Polyurethane Phase Separated to Nano Size in an Epoxy Polymer
}

\author{
Taehee Kim, Miri Kim, Wonju Lee, Hyeon-Gook Kim, Choong-Sun Lim * and Bongkuk Seo * \\ The Center for Chemical Industry Development, Korea Research Institute of Chemical Technology, 45, \\ Jongga-ro, Yugok-dong, Jung-gu, Ulsan 44412, Korea; kimth@krict.re.kr (T.K.); miri@krict.re.kr (M.K.); \\ winston@krict.re.kr (W.L.); candoit@krict.re.kr (H.-G.K.) \\ * Correspondence: chsunlim@krict.re.kr (C.-S.L.); bksea@krict.re.kr (B.S.); Tel.: +82-52-241-6021 (C.-S.L.)
}

Received: 15 February 2019; Accepted: 15 March 2019; Published: 15 March 2019

\begin{abstract}
Epoxy resins are widely applicable in industries such as aircraft, automobiles, coatings, and adhesives because of their good chemical resistance and excellent mechanical and thermal properties. However, on an external impact, the crack propagation of epoxy polymers weakens the overall impact resistance of the materials. Therefore, many impact modifiers have been developed to reduce the brittleness of epoxy polymers. Polyurethanes as an impact modifier can improve the toughness of polymers. Although it is known that polyurethanes are phase-separated in the polymer matrix after curing, connecting polyurethanes to the polymer matrix has been problematic for enhancing the mechanical properties of polymers. In this study, we introduced epoxy functional groups into polyol backbones, which is different from other studies that focused on modifying capping agents to achieve a network structure between the polymer matrix and polyurethane. We confirmed the molecular weight of the prepared polyurethane with gel permeation chromatography. Moreover, the prepared material was added to the epoxies to evaluate the changes in the mechanical and thermal properties of the materials. Furthermore, we conducted tensile, flexural strength, and impact resistance measurements. The experimental results are discussed in detail.
\end{abstract}

Keywords: epoxy resin; polyurethane; physical properties

\section{Introduction}

Epoxy resins are thermosetting polymers that form 3D network structures after exothermic reactions with amine or acidic anhydride hardeners [1,2]. Epoxy resins are interesting due to their excellent mechanical and thermal properties and chemical resistance [3-6]. One main disadvantage of the resins is brittleness, which easily allows crack propagations upon outside impact.

Therefore, many studies have been conducted to overcome this weakness by adding toughening agents that enhance the impact resistance. In general, rubbery resins, such as carboxyl-terminated butadiene (CTBN) [7] and amine-terminated butadiene (ATBN) [8], are used as toughening agents, whereas thermoplastic polyethersulfone [9] and polyetherimide [10] have been partially applied. Elastomeric polyurethanes are representative tougheners for thermosetting polymers. Polyurethanes are composed of a soft segment of polyol and a hard segment of diisocyanate [11], which are not compatible with each other and lead to phase separation.

By the addition of polyurethanes in other polymers, the mechanical properties are enhanced because of networking the two polymers. The interaction between polyurethane (PU) and the epoxy matrix is usually achieved by mixing PU, which has -NCO functional groups, with epoxy, which has a hydroxyl group [12,13], or reacting polyol with diisocyanate in the presence of fillers [14,15].

In this study, polyols with epoxy groups were designed to react with amine or epoxy groups in a bridged PU and epoxy matrix. Therefore, a fatty acid-modified epoxy polyol was reacted with 
diisocyanate to synthesize PU not only to increase the impact resistance but also to maintain the mechanical properties. Furthermore, the toughening properties of the PU on the epoxy compositions were tested. Different amounts of PU were poured into the epoxy materials and cured to form thermosetting polymers to evaluate the mechanical properties with a universal testing machine (UTM) and the viscoelastic properties via dynamic mechanical analysis (DMA). Furthermore, the fracture surface of the test specimen was observed with field emission scanning electron microscopy (FE-SEM) and transmission electron microscopy (TEM).

\section{Experiments}

\subsection{Materials}

Diglycidyl ether of bisphenol A (DGEBA, YD-128, epoxy equivalent weight (EEW, g/eq unit), $187 \mathrm{~g} / \mathrm{eq}$ ), and a hydrogenated epoxy resin named ST-3000 (EEW, $228.6 \mathrm{~g} / \mathrm{eq}$ ) were obtained from Kukdo Chemical. D-230 (polyether diamine, M.W. $230 \mathrm{~g} / \mathrm{mol}$ ) was also purchased from Kukdo Chemical. A dimeric fatty acid (pripol 1013-LQ, M.W. 560 g/mol) was obtained from Croda Europe, LTD (Korea branch). Polypropylene glycol (PPG, M.W. 2000 g/mol), dibutyltin dilaurate (DBTDL), 2-hydroxyethyl methacrylate (HEMA), and isophorone diisocyanate (IPDI) were purchased from Sigma-Aldrich (Saint Louis, MI, USA).

\subsection{Synthesis of Polyol: Modification of Hydrogenated Epoxy Resin with Fatty Acid}

Dimeric fatty acid (45 g, $0.08 \mathrm{~mol})$ was reacted with ST-3000 (73 g, $0.16 \mathrm{~mol})$ in a $200 \mathrm{~mL}$ reactor at $100{ }^{\circ} \mathrm{C}$ for $40 \mathrm{~min}$ while triphenyl phosphine $(0.3 \mathrm{~g})$ was added as a catalyst (Figure 1$)$ The product was cooled to room temperature followed by analysis via ${ }^{1} \mathrm{H}-\mathrm{NMR}$ and FT-IR to confirm that the reaction was completed to produce the fatty-acid-modified hydrogenated epoxy polyol (FMEP).
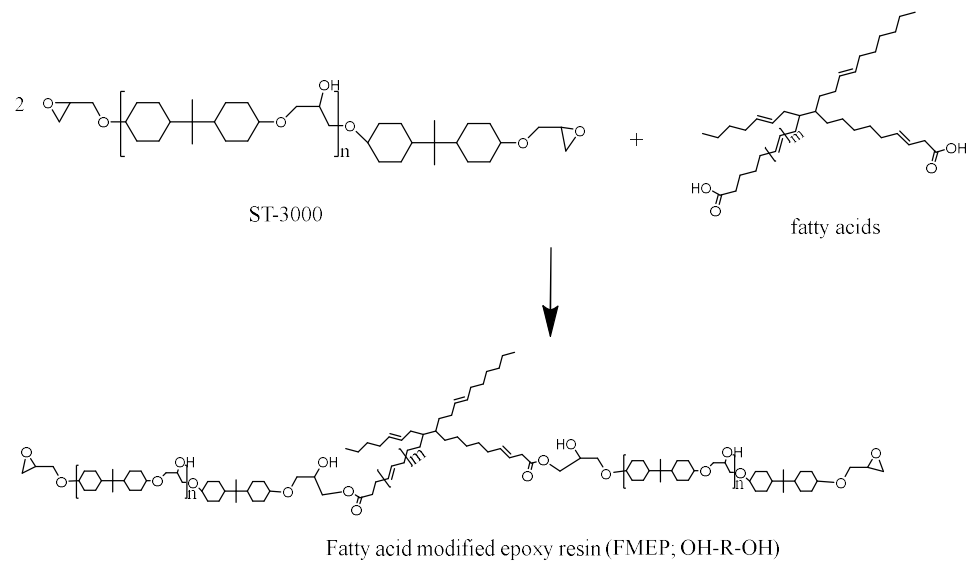

Figure 1. Reaction scheme of the fatty acid-modified epoxy resin to synthesize the polyol.

\subsection{Synthesis of Polyurethane using FMEP (FMEP-PU)}

FMEP (60 g, $0.04 \mathrm{~mol})$, polypropylene glycol $(20 \mathrm{~g}, 0.04 \mathrm{~mol})$, and IPDI $(9.8 \mathrm{~g}, 0.16 \mathrm{~mol})$ were added into a reactor and stirred for $40 \mathrm{~min}$ at $80{ }^{\circ} \mathrm{C}$ under nitrogen as the catalyst, DBTDL, was added. Then, 2-hydroxyethyl methacrylate (HEMA, $21 \mathrm{~g}$, $0.16 \mathrm{~mol}$ ) was added to cap the terminal NCO group, and the solution was stirred for $3 \mathrm{~h}$ at $80^{\circ} \mathrm{C}$. The reaction scheme is displayed in Figure 2 . 


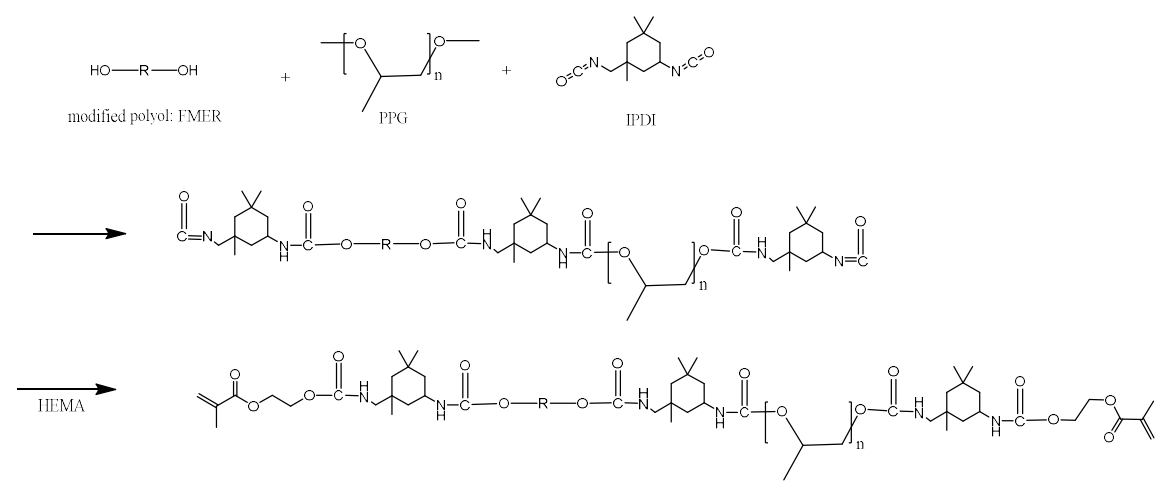

Figure 2. Reaction scheme for polyurethane by reacting the fatty acid-modified hydrogenated epoxy polyol with isophorone diisocyanate.

\subsection{Preparation of Epoxy Compositions and Cured Thermosetting Plastics}

The epoxy resin and D-230 were stoichiometrically mixed based on the equivalent molar ratio (Equation (1)). The amount of MHEF in the epoxy resin was varied from 5 to 15 parts by weight per 100 parts of epoxy resin (phr). Formulation information for the epoxy compositions is summarized in Table 1.

$$
\{100 \mathrm{~g} \text { (of epoxy resin) }\} /\{187 \text { (g/epoxy resin) }\} \times 60 \text { (amine hydrogen equivalent wt.) }
$$

The epoxy resin and FMEP-PU were mixed and stirred for $20 \mathrm{~min}$ at $40{ }^{\circ} \mathrm{C}$ followed by the addition of D-230 for $20 \mathrm{~min}$. The prepared paste was poured into a metal mold. The metal mold was placed in an oven and heated for $1 \mathrm{~h}$ at $80^{\circ} \mathrm{C}$ to polymerize the epoxy resin and the amine hardener.

Table 1. Formulation information for the epoxy compositions.

\begin{tabular}{ccccc}
\hline Samples & Binder $(g)$ & PU-5 (g) & PU-10 (g) & PU-15 (g) \\
\hline EPIKOTE 828 & 100 & 100 & 100 & 100 \\
Jeffamine D-230 & 32.1 & 32.1 & 32.1 & 32.1 \\
FMEP-PU & - & 5 & 10 & 15 \\
\hline
\end{tabular}

\subsection{Measurements and Analysis}

The synthesized FMEP and FMEP-PU were analyzed by Fourier transform-infrared spectrometry (FT-IR, Nicolet 6700/ Nicolet Continuum; Thermo Fisher Scientific Inc., Walthum, MA, USA) and gel permeation chromatography (GPC, 1260 series, Agilent Technologies, New York, NY, USA).

The cured epoxy polymers in the metal mold were processed to achieve a $60 \mathrm{~mm} \times 25 \mathrm{~mm} \times 3 \mathrm{~mm}$ test specimen used to measure the flexural strength based on the ASTM D $790 \mathrm{M}$ standard [16] by using a grinding machine (BESTPOL P2b2; SSAUL Bestech Co., Seoul, Korea) and a diamond cutter (Manix, MBS 500/E; Woosung E\&I Co., Pyeongtaek-si, Korea). Additionally, the test specimen for the tensile strength measurement was also processed to a size of $150 \mathrm{~mm} \times 13 \mathrm{~mm} \times 3 \mathrm{~mm}$. The mechanical strength was tested with 10 specimens per condition with the UTM (UTM 5982, INSTRON, Norwood, MA, USA), and the mean value (excluding the maximum and minimum values) was used. The impact strength was measured with an Izod impact tester (JJHBT-6501, JJ-test, Chengde, China) based on the ASTM D 256 method [17].

The viscoelastic properties of the cured polymers were evaluated by subjecting a $60 \times 12 \times 3 \mathrm{~mm}^{3}$ sample to dynamic mechanical analysis (DMA, Q800, TA Instruments, Inc., New Castle, DE, USA). The test sample was mounted on the dual cantilever probe and tested under the condition of a heating rate of $5{ }^{\circ} \mathrm{C} / \mathrm{min}$ in the range of $25-200^{\circ} \mathrm{C}$ at a frequency of $1 \mathrm{~Hz}$ to measure both the storage moduli and tan $\delta$ values. The fractured surface obtained during the impact test was observed by FE-SEM (MIRA 3, TESCAN, Brno, Czech Republic) and FE-TEM (JEM-2010, JEOL, Tokyo, Japan). 


\section{Results and Discussion}

\subsection{Modification of the Epoxy Resin (FMEP)}

The prepared FMEP was analyzed by FT-IR as shown in Figure 3. The FT-IR results showed that the fatty acid carbonyl $(\mathrm{C}=\mathrm{O})$ peak at $1708 \mathrm{~cm}^{-1}$ shifted to $1740 \mathrm{~cm}^{-1}$ upon the reaction between the hydroxyl group of acid in the fatty acid and the epoxy group of ST-3000 (see Figure 1). A chemical shift in the hydroxyl group of ST-3000 was observed from $3413 \mathrm{~cm}^{-1}$ to $3472 \mathrm{~cm}^{-1}$ upon the reaction as well as an intensity increase. The EEW of FMEP that was measured using the ASTM D1652 method also was 722 EEW, which is similar to the theoretical value (736 EEW) for the complete reaction.

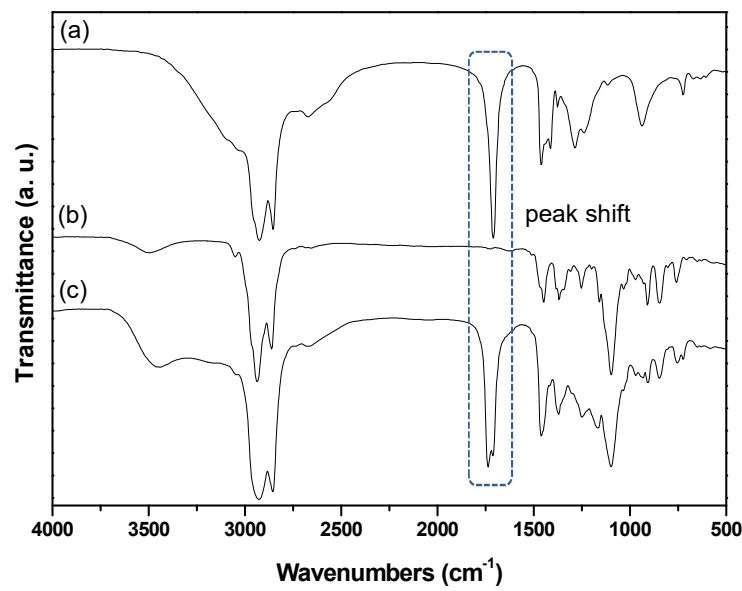

Figure 3. IR spectrum of (a) the fatty acid, (b) ST-3000, and (c) the fatty acid-modified hydrogenated epoxy polyol.

\subsection{Synthesis of Polyurethane}

The prepared polyol, FMEP, was mixed with PPG in a 1:1 molar ratio before the mixed polyol was reacted with IPDI to form polyurethane. The ratio of the mixed polyol to IPDI was 1:2. Therefore, the terminal isocyanate group was observed at $2270 \mathrm{~cm}^{-1}(-\mathrm{N}=\mathrm{C}=\mathrm{O})$ in the FT-IR spectrum, as shown in Figure 4a, whereas the isocyanate peak showed a minimum amount of -NCO (Figure $4 \mathrm{~b}$ ) after the reaction with HEMA. The molecular weights of the PU obtained with GPC were as follows: the number average molecular weight $(\mathrm{Mn})=6,665 \mathrm{~g} / \mathrm{mol}$ and the weight molecular weight $(\mathrm{Mw})=51,260 \mathrm{~g} / \mathrm{mol}$ with 7.7 of polydispersity index (PDI) in Figure 5 .

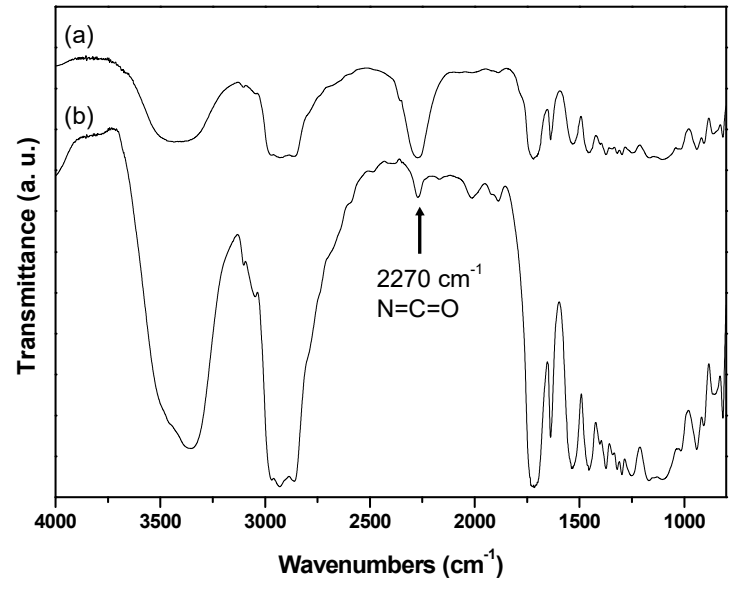

Figure 4. IR spectrum of polyurethane when removed (a) before mixing with the capping agent and (b) after $3 \mathrm{~h}$ of mixing with the capping agent. 


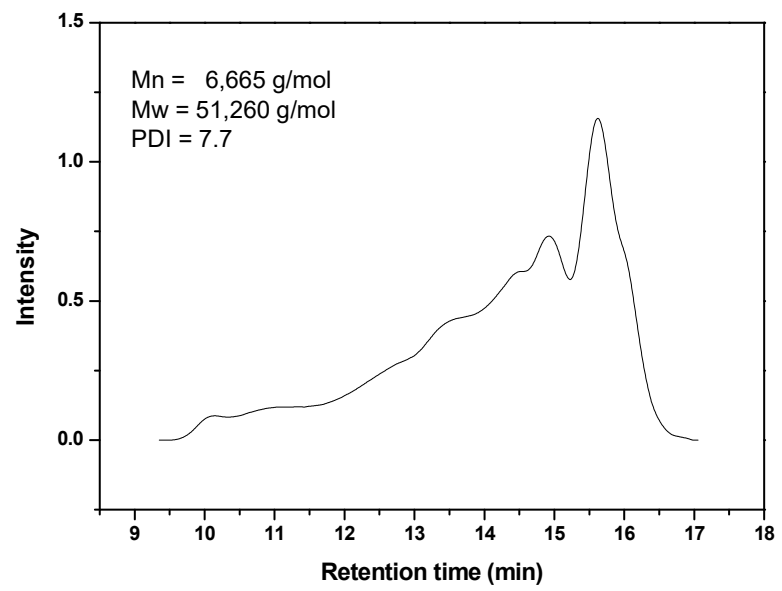

Figure 5. Gel permeation chromatogram of polyurethane.

\subsection{Mechanical Properties of the Cured Epoxy Polymer}

The mechanical properties, such as tensile, flexural, and impact strengths, of the cured epoxy polymers were measured by UTM, as shown in Figure 6. Epoxy polymers have excellent mechanical properties but have brittleness that easily causes crack propagation. Therefore, the synthesized PU was added to the epoxy compositions as a toughening agent to restrain cracks. The viscous liquid PU was well mixed with the compositions and was phase-separated when the pastes formed a solid polymer after the curing reaction at high temperature. However, when the PU phase-separated, it lowered the cross-linking density of the polymer and reduced the mechanical properties. Therefore, the decrease in tensile or flexural strength is proportional to the amount of PU added into the epoxy compositions. To increase the strength, the synthesized PU as designed to have glycidyl groups to bridge the PU to the epoxy polymer via a reaction between the epoxy groups of PU and the amine groups of the hardeners. As shown in Figure 6a, the tensile strength increased when $10 \%$ PU was added; however, it decreased when $15 \%$ PU was added. For flexural strength (Figure $6 \mathrm{~b}$ ), even $5 \%$ addition of PU increased the strength, and it maintained with $10 \%$ addition. However, it decreased with 15\% PU addition. The impact strength data (Figure 6c) show that the impact strength of epoxy polymers begins to increase when $10 \%$ PU is added.

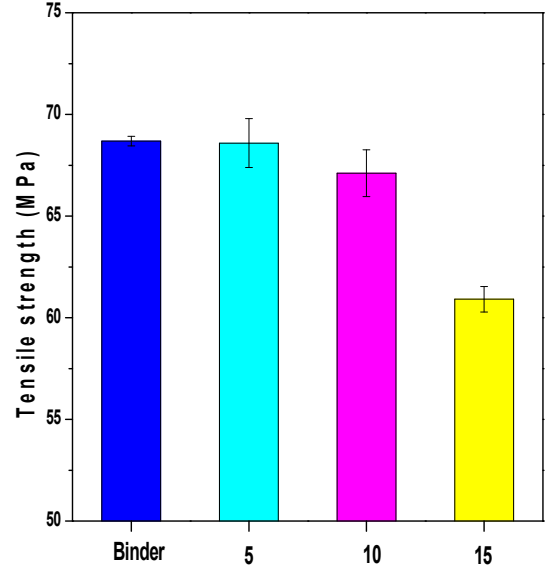

(a)

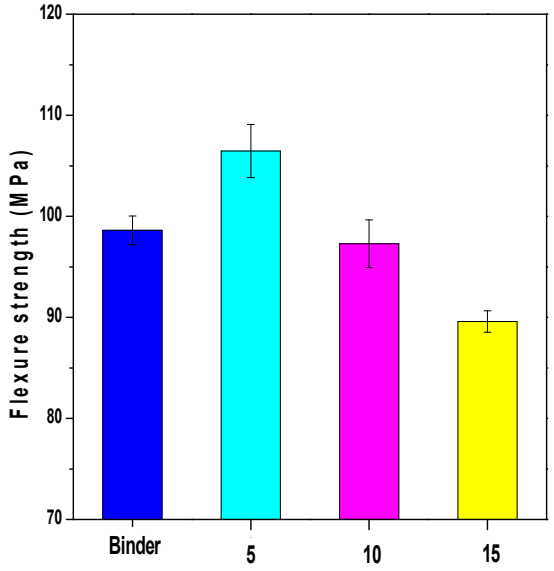

(b)

Figure 6. Cont. 


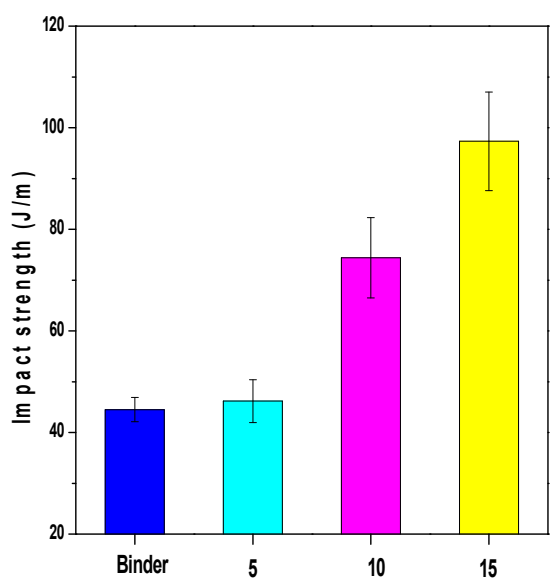

(c)

Figure 6. Cured epoxy polymers: (a) tensile strength; (b) flexural strength; and (c) impact strength.

\subsection{Dynamic Mechanical Analysis of Epoxy Polymers}

The viscoelastic properties of the cured epoxy polymers were subjected to DMA. The obtained storage modulus, loss modulus, and tan $\delta$ data are shown in Figure 7 . The initial storage modulus at $25^{\circ} \mathrm{C}$ for the epoxy polymers increased from 2,035 to 3,000 MPa upon the addition of PU, while the storage modulus of the polymers decreased upon an increase in temperature. As shown in Figure 7c, the glass transition temperature $(\tan \delta)$ of PU- 5 abruptly decreased as the tan $\delta$ of PU-10 and PU-15 showed a higher temperature than that of PU-5. This indicates that the cyclohexyl groups of the modified polyol provide rigidity to PU.

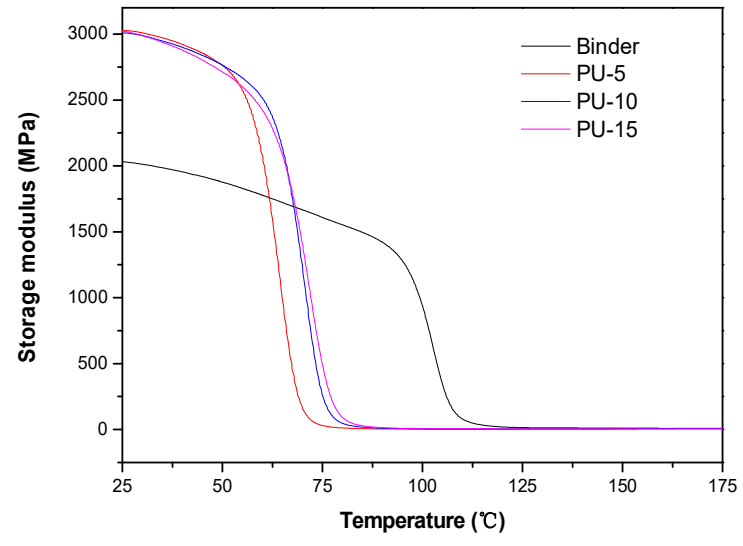

(a)

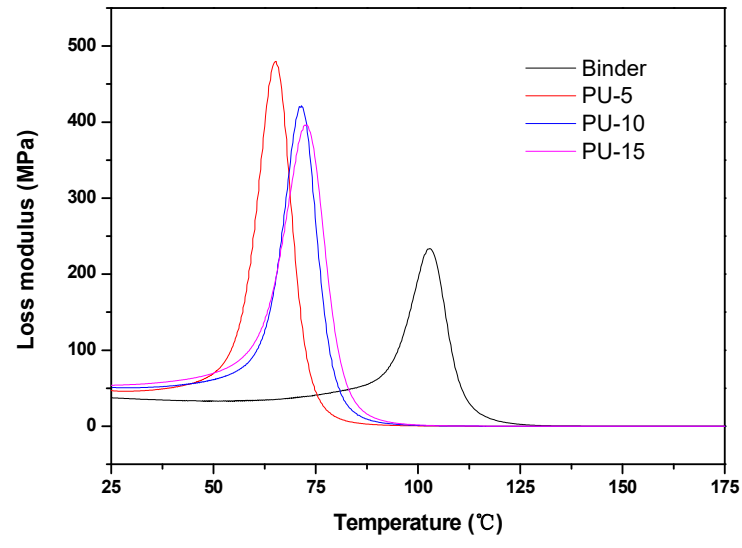

(b)

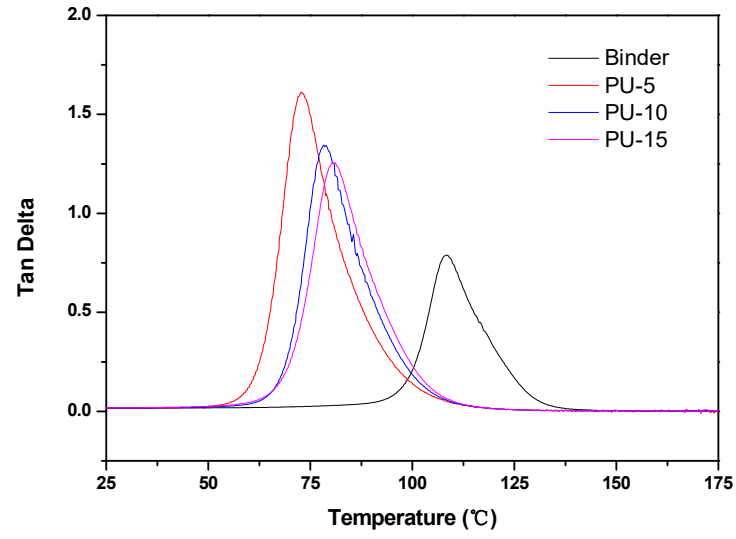

(c)

Figure 7. DMA data of the cured epoxy polymers: (a) storage modulus; (b) loss modulus; and (c) tanঠ. 


\subsection{FE-SEM Images of Fractured Epoxy Polymers Obtained after Impact Tests}

FE-SEM images of the fractured cured epoxy matrix were observed, as shown in Figure 8. The surface of the neat resin looks smooth, whereas the fractured surfaces of the epoxy polymers, including PU, have small holes that are $100 \mathrm{~nm}$ in size. The holes are traces from when the phase-separated PU particles bounced off due to the impact. In addition, it is also possible that a similar size of protruding parts is observed, indicating that a strong interaction between the epoxy matrix and PU particles occurred when the system was cured.
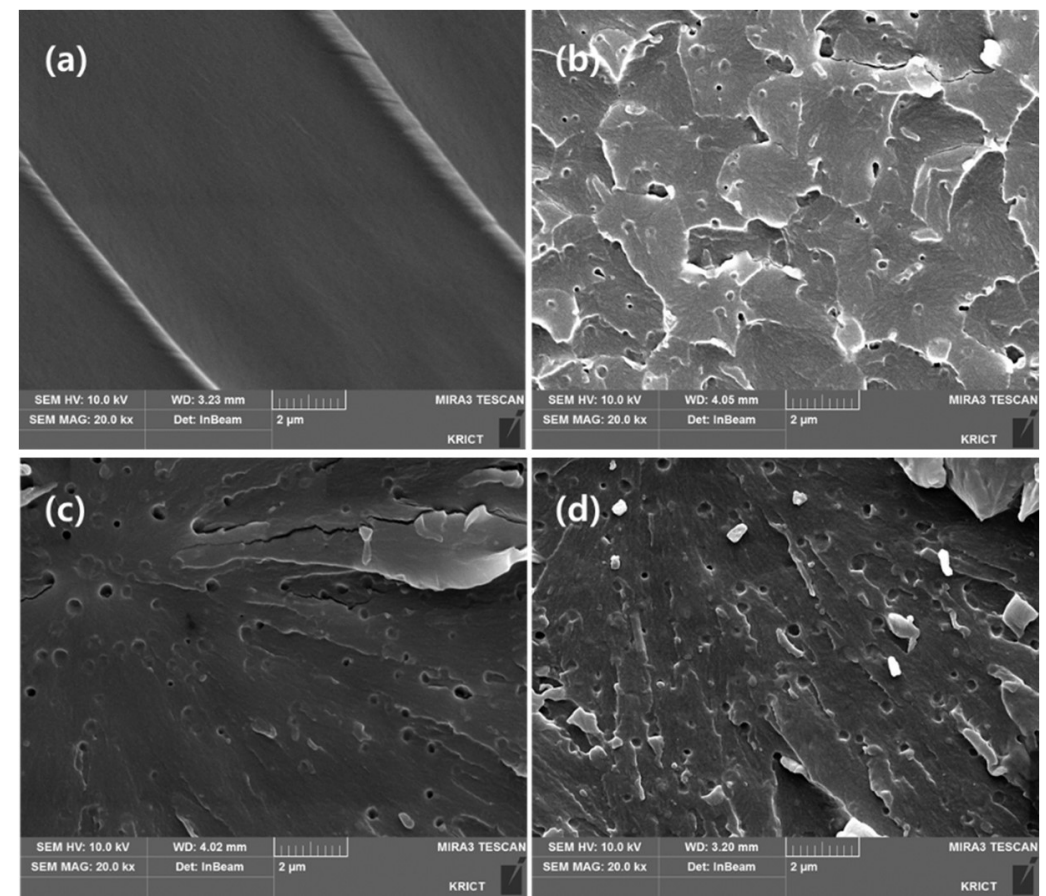

Figure 8. FE-SEM images of the fractured surfaces: (a) binder; (b) PU-5; (c) PU-10; and (d) PU-15.

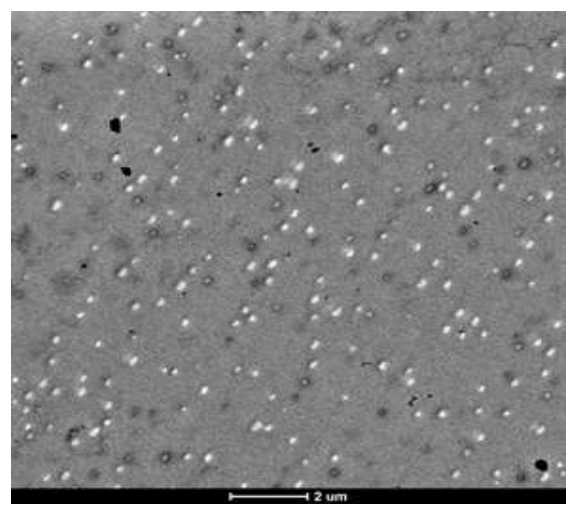

Figure 9. TEM image of PU-15.

\section{Conclusions}

In this study, the bisphenol A epoxy resin was modified with a dimeric fatty acid, both having polyol and diglycidyl groups. The prepared polyol was mixed with PPG and reacted with IPDI followed by the addition of HEMA to form stable elastomeric PU. The synthesized PU was used as a toughener for the epoxy system to compensate for the brittleness of the epoxy polymer formed by curing. Various amounts of PU were added into the epoxy compositions and cured at high temperature to form the epoxy polymer. Mechanical tests were conducted to confirm the change in mechanical properties, including tensile and flexural strength tests and impact strength tests. The experimental data show that the PU maintained the mechanical properties of cured epoxy matrix 
upon $10 \%$ addition without considerable reduction, while it increases the impact strength of the polymers by more than a factor of two proportional to the amount of PU content.

Author Contributions: Conceptualization, B.S. and C.-S.L.; Methodology, B.S. and C.-S.L.; Formal Analysis, W.L. and H.-G.K.; Investigation, T.K.; Writing-Original Draft Preparation, B.S. and C.-S.L.; Writing-Review \& Editing, B.S. and C.-S.L.

Funding: This research (No. SI1941-20; Development of specialty chemicals for automobile industry) was funded by the Korea Research Institute of Chemical Technology (KRICT), the Ministry of Trade, Industry and Energy(MOTIE), and Korea Institute for Advancement of Technology(KIAT) through the National Innovation Cluster R\&D program(P0006669_ Development of Fiber-reinforced Composite Based Floor Cover for Micro Electric Vehicle Platform).

Conflicts of Interest: The authors declare no conflict of interest.

\section{References}

1. Toldy, A.; Szebényi, G.; Molnár, K.; Tóth, L.F.; Magyar, B.; Hliva, V.; Czigány, T.; Szolnoki, B. The Effect of Multilevel Carbon Reinforcements on the Fire Performance, Conductivity, and Mechanical Properties of Epoxy Composites. Polymers 2019, 11, 303.

2. Fombuena, V.; Petrucci, R.; Dominici, F.; Jordá-Vilaplana, A.; Montanes, N.; Torre, L. Maleinized Linseed Oil as Epoxy Resin Hardener for Composites with High Bio Content Obtained from Linen Byproducts. Polymers 2019, 11, 301.

3. Chu, W.-C.; Lin, W.-S.; Kuo. S.-W. Flexible Epoxy Resin Formed Upon Blending with a Triblock Copolymer through Reaction-Induced Microphase Separation. Materials 2016, 9, 449-459.

4. Greiner, L.; Kukla, P.; Eibl, S.; Döring, M. Phosphorus Containing Polyacrylamides as Flame Retardants for Epoxy-Based Composites in Aviation. Polymers 2019, 11, 284.

5. Zhang, C.; Dai, X.; Wang, Y.; Sun, G.; Li, P.; Qu, L.; Sui, Y.; Dou, Y. Preparation and Corrosion Resistance of ETEO Modified Graphene Oxide/Epoxy Resin Coating. Coatings 2019, 9, 46.

6. Cheng, Y.; Zhang, Q.; Fang, C.; Chen, J.; Su, J.; Xu, K.; Ai, L.; Liu, D.; Preparation, Structure, and Properties of Surface Modified Graphene/Epoxy Resin Composites for Potential Application in Conductive Ink. Coatings 2018, 8, 387.

7. Wise, C.W.; Cook, W.D.; Goodwin, A.A. CTBN rubber phase precipitation in model epoxy resins. Polymer 2000, 41, 4625-4633.

8. Chikhi, N.; Fellahi, S.; Bakar, M. Modification of epoxy resin using reactive liquid (ATBN) rubber. Eur. Polym. J. 2002, 38, 251-264.

9. Yun, N.G.; Won, Y.G.; Kim, S.C. Polyether sulfone: Toughening of carbon fiber/epoxy composite by inserting polysulfone film to form morphology spectrum. Polymer 2004, 45, 6953-6958.

10. Su, C.C.; Wu, C.C.; Yang. C.F. Developing the dielectric mechanisms of polyetherimide/multiwalled carbon nanotube/ (Ba0.8Sro.2)(Tio.. Zro.1) $\mathrm{O}_{3}$ composites. Nanoscale Res. Lett. 2012, 7, 132.

11. Li, B.; Shao, W.; Wang, Y.; Xiao, D.; Xiong, Y.; Ye, H.; Zhou, Q.; Jin, Q. Synthesis and Morphological Control of Biocompatible Fluorescent/Magnetic Janus Nanoparticles Based on the Self-Assembly of Fluorescent Polyurethane and $\mathrm{Fe}_{3} \mathrm{O}_{4}$ Nanoparticles. Polymers 2019, 11, 272.

12. Chen, C.H.; Chen, M.H. Synthesis, Thermal Properties, and Morphology of Blocked Polyurethane/Epoxy Full-Interpenetrating Polymer Network. J. Appl. Polym. Sci. 2006, 100, 323-328.

13. Chen, C.H.; Sun, Y.Y. Mechanical Properties of Blocked Polyurethane/Epoxy Interpenetrating Polymer Networks. J. Appl. Polym. Sci. 2006, 101, 1826-1832.

14. Zhu, Y.C.; Wang, B.; Gong, W.; Kong, L.M.; Jia, Q.M. Investigation of the hydrogen bonding structure and miscibility for PU/EP IPN nanocomposites by PALS. Macromolecules 2006, 39, 9441-9445.

15. Sahu, M.; Raichur, A.M. Toughening of high performance tetrafunctional epoxy with poly(allylamine) grafted graphene oxide. Compos. Part B 2019, 168, 15-24.

16. ASTM D790-17 Standard Test Methods for Flexural Properties of Unreinforced and Reinforced Plastics and Electrical Insulating Materials; ASTM International: West Conshohocken, PA, USA, 2017.

17. ASTM D256-10(2018) Standard Test Methods for Determining the Izod Pendulum Impact Resistance of Plastics; ASTM International: West Conshohocken, PA, USA, 2018. 
(c) 2019 by the authors. Licensee MDPI, Basel, Switzerland. This article is an open access article distributed under the terms and conditions of the Creative Commons Attribution (CC BY) license (http://creativecommons.org/licenses/by/4.0/). 